\title{
Characteristics of freeze-dried nanoencapsulated fish oil with whey protein concentrate and gum arabic as wall materials
}

\author{
Farideh VAHIDMOGHADAM ${ }^{1}$, Rezvan POURAHMAD ${ }^{2 *}$ (D), Ali MORTAZAVI ${ }^{1}$, Daryoush DAVOODI ${ }^{3}$, \\ Reza AZIZINEZHAD ${ }^{4}$
}

\begin{abstract}
Fish oil has many health effects, but due to its strong odor and rapid spoilage, its use in food formulations is limited. For these reasons, nanoencapsulation of fish oil can be important. The purpose of this study was to investigate the influence of whey protein concentrate (WPC) and gum arabic as wall materials on the characteristics of nanoencapsulated fish oil powder. Gum arabic and WPC were used in varying amounts for nanoencapsulation of fish oil. An oil-in-water emulsion with $6 \%$ fish oil and $20 \%$ aqueous solution of wall materials was prepared by sonication $(24 \mathrm{kHz}$ for $120 \mathrm{sec})$. The diameter of the emulsion droplets was measured by particle size analysis and they then were dried in a freeze-drier. The results showed that the type and concentration of wall material influenced the characteristics of the nanocapsules. The smallest emulsion droplet diameter $(50 \mathrm{~nm})$ and the highest encapsulation efficiency were found in the sample containing $100 \%$ gum arabic; however, the lowest amount of surface oil, $\mathrm{pH}$ and highest zeta potential and moisture content also were recorded for this sample. It can be concluded that gum arabic is more suitable for nanoencapsulation and could appropriately contain the volatile compounds within the capsules.
\end{abstract}

Keywords: encapsulation; fish oil; gum arabic; nano-emulsion; whey protein concentrate.

Practical Application: In this study, freeze-dried nanoencapsulated fish oil with gum arabic and whey protein concentrate as wall materials was prepared. It was shown that gum arabic was more suitable for nanocapsulation and could appropriately maintain volatile compounds within capsules. Thisnanoencapsulated fish oil can be usedfor fortification of low-fat foods or producing functional foods.

\section{Introduction}

Knowledge about the possible hazards of fatty foods has increased demand for low-calorie and low-fat products, preferably those rich in dietary fiber. This decreases the percentage of fat-soluble nutrients such as vitamins A, D, E and K, antioxidants and poly-unsaturated fatty acids (Considine et al., 2007). Omega-3 is a type of polyunsaturated fatty acid which plays an important role in cardiovascular health. Linoleic acid, eicosapentaenoic acid(EPA) and docosahexaenoic acid(DHA) are the most important omega-3 fatty acids and are found primarily in seafood and plants products such as walnuts, rapeseed and flaxseed (Lopez-Huertas, 2010). Omega- 3 fatty acids can be used for fortification of low-fat food or production of functional foods, but because these fatty acids are hydrophobic and practically insoluble in water, it is difficult to use them for beverage fortification. Because of their unsaturated bonds, these components are highly sensitive to oxidative degradation and develop an inappropriate odor and taste; moreover, their beneficial properties decrease. Utilization of nano-carriers (encapsulation) for transferring and protection of lipid-soluble components is a suitable way of overcoming these difficulties (Liu et al., 2008).
Nanoencapsulation is a technique in which carriers of less than $100 \mathrm{~nm}$ in size are produced and utilized to fortify food and transfer nutrients, nutraceuticals or bioactive components such as fatty acids, antioxidants and carotenoids to target sections (Ye et al., 2006). The material used to form the nanocapsule depends on its usage and can be either a biopolymer or polymer. Proteins, polysaccharides and their combination have been used to produce biopolymer nano-carriers (Zimet \& Livney, 2009). Carbohydrates also have been used as wall components or carrier material for nanoencapsulation. These include gums, starches, maltodextrin and corn syrup because they are inexpensive, have appropriate solubility and induce low viscosity in high concentrations (Mutka \& Nelson, 1988).

Gum arabic is the most important gum used in nanoencapsulation of flavoring components. Suitable solubility, low viscosity, good emulsification ability, high flavor and lipid-drop holding capacity make this gum appropriate (Shiga et al., 2001). Food proteins like sodium caseinate, whey protein and soy protein isolate have also been used as walls for nanoencapsulation. Their different

${ }^{1}$ Department of Food Science and Technology, Sabzevar Branch, Islamic Azad University, Sabzevar, Iran

${ }^{2}$ Department of Food Science and Technology, College of Agriculture, Varamin-Pishva Branch, Islamic Azad University, Varamin, Iran

${ }^{3}$ Nanotechnology Department, Agricultural Biotechnology Research Institute of Iran - ABRII, Agricultural Research, Education and Extension Organization - AREEO, Karaj,

Iran

${ }^{4}$ Department of Plant Breeding, College of Agriculture and Natural Resources, Science and Research Branch, Islamic Azad University, Tehran, Iran

*Corresponding author: rjpourahmad@yahoo.com, rezvanpourahmad@iauvaramin.ac.ir 
functional groups, amphiphilic properties, self-assembling and self-structuring abilities, interaction with components, high molecular weight and flexibility of the protein chains produce suitable functional properties such as solubility, viscosity, emulsifying capacity and layer-forming ability (Dickinson, 2003).

The functional properties of whey protein make it suitable for capsule walls. Utilization of whey protein in nanoencapsulation has been investigated by many researchers. In addition to the use of whey protein alone or in combination with other proteins, carbohydrates have been used for encapsulation of aromatic components. In these systems, whey protein is used as an emulsifier and layering agent, but carbohydrates such as maltodextrin and corn syrup are used to form networks and other layers (Rosenberg, 1997).

The advantages of biopolymer nanocapsules for hydrophobic nutraceuticals are that they enhance the solubility of the hydrophobic ingredients in beverages, protect these materials from environmental deterioration (from oxygen and light), control their release in food and the body, prevent formation of off-odors in food and increase bio-accessibility (Philips \& Williams, 2000).

Some researchers have investigated the efficiency of nanoencapsulation of fish oil. The nanoparticles were prepared by spray-drying or high-energy emulsification techniques, such as microfluidization and ultrasound. Maltodextrin combined with biopolymers (modified starch or whey protein concentrate) at a ratio of 3:1 has been used as wall material. The results showed that microfluidization is an efficient technique for emulsification and capsulated the fish oil powder at the lowest oil content at the surface of the particles, allowing emulsification in the nano-range (210-280 nm) (Jafari et al., 2008). Another study produced nanocapsules of alpha-linoleic acid using the modified emulsion diffusion technique with an encapsulation efficiency of $93 \%$. Polylactic acid was used as the encapsulating polymer with acetone and ethyl acetate as organic solvents and Tween 20, gelatin and pluronic-F68 in the water as stabilizers. Two organic/aqueous phase ratios were used with the solvent and stabilizer. Nanocapsule dispersions of less than $100 \mathrm{~nm}$ in size with a zeta potential of $33 \mathrm{mV}$ were obtained. Acetone, as compared to ethyl acetate, and Tween 20 , as compared to pluronic-F68 and gelatin, were effective for producing smaller capsules (Habib et al., 2012).

Because fish oil is used in food and in pharmaceutical and cosmetic formulations, basic investigation is required to provide information about its utilization in such formulations. In this study, gum arabic and whey protein concentrate were used as wall materials for nanoencapsulation of fish oil as an omega-3 fatty acid source as opposed to the wall materials used for nanoencapsulation or microencapsulation by other researchers. Moreover, ultrasound was used for different lengths of time and frequencies in contrast to the use of ultrasound or homogenization and coacervation in previous studies. To minimize the negative effect of thermal processing during spray-drying, freeze-drying was applied. The purpose of this study was to investigate the characteristics of freeze-dried nanoencapsulated fish oil with whey protein concentrate and gum arabic as wall materials.

\section{Materials and methods}

\subsection{Materials}

Fish oil was purchased from Nosh-DaroDaria. Gum arabic $\left(\right.$ density $\left.=1.4 \mathrm{~g} / \mathrm{cm}^{3}\right)$, sorbitol mono-9-octadecnoat (Tween 80 ), ethanol, n-hexane, 2-propanol and other chemical substances (of experimental purity) were purchased from Merck (Germany). Whey protein concentrate (WPC; $80 \%$ protein) was purchased from Mill Haven Foods (USA). Deionized water was used for preparation of solutions.

\subsection{Preparation of nano-emulsion}

In this study, the wall material (gum arabic + WPC) was consistently $20 \%$. The solutions of gum arabic plus WPC were prepared in the following ratios: $0: 20,10: 10,12: 8,16: 4,20: 0$. The mixture was stirred with a magnetic stirrer $(500 \mathrm{rpm}$ at $60^{\circ} \mathrm{C}$ for $1 \mathrm{~h}$ ). The solutions were left for $24 \mathrm{~h}$ at refrigerator temperature to maximum hydration. Tween $80(2 \% \mathrm{w} / \mathrm{w})$ and fish oil $(6 \% \mathrm{w} / \mathrm{w})$ were slowly added and the mixtures were immediately stirred for $30 \mathrm{~min}$ at $500 \mathrm{rpm}$ with a magnetic stirrer. The nanoemulsion was produced by sonication $(24 \mathrm{kHz}$ for $120 \mathrm{sec}$ ) (Saberi et al., 2014).

\subsection{Size of emulsion droplets}

The particle size distribution was determined by dynamic light scattering (DLS; Malvern; UK) to measure the average diameter of the emulsion droplets.

\section{4 pH measurement}

The $\mathrm{pH}$ of the nanoemulsions was measured using the AOAC method with a pH meter (Metrohm 827; Switzerland) (Association of Official Analytical Chemists, 2000).

\subsection{Zeta potential}

The zeta potential was determined at $25^{\circ} \mathrm{C}$ and $149 \mathrm{~W}$ in a Zetasizer Nano ZS device (UK).

\subsection{Nanoencapsulation and freeze drying}

Emulsions were frozen at $-20^{\circ} \mathrm{C}$ for $24 \mathrm{~h}$ and then placed in a freeze-drier (Zirbus, Germany) for $48 \mathrm{~h}$ at $-50^{\circ} \mathrm{C}$. Dried samples were ground into fine powder with a mortar and pestle (Kaushik \& Roos, 2007).

\subsection{Moisture content}

Moisture content was measured after drying in an oven at $102^{\circ} \mathrm{C}$ (Saberi et al., 2014).

\subsection{Extraction of surface and total oil of powders}

Hexane $(8 \mathrm{ml})$ was added to $1 \mathrm{~g}$ of sample powder and mixed for $2 \mathrm{~min}$, then centrifuged at $8000 \mathrm{rpm}$ for $20 \mathrm{~min}$. The supernatant was filtered through filter paper and the solvent was evaporated at $70^{\circ} \mathrm{C}$. The extracted oil was dried at $50^{\circ} \mathrm{C}$ until a constant weight was reached (Klinkesorn et al., 2006). The total 
oil was extracted as follows: solvent (3:1 isopropanol:hexane) was added to $0.5 \mathrm{~g}$ of powder, stirred for $5 \mathrm{~min}$ and the clear organic solution phase was evaporated at $70^{\circ} \mathrm{C}$ until a constant weight was achieved (Jimenez et al., 2004). The encapsulation efficiency was calculated according to method described by Wang et al. (2006) (Equation 1).

$$
\mathrm{EE} \%=[\text { Total oil- Surface oil/Total oil }] * 100
$$

\subsection{Statistical analysis}

Experiments were conducted in a 3-factor fully randomized design. Because there were two wall materials comprising five different combinations, the experiments were done in triplicate. Microsoft Excel was used for drawing the graphs. Statistical analysis was conducted in SPSS 23 software using Duncan's multiple range test at a $95 \%$ confidence level for significance.

\section{Results and discussion}

\section{$3.1 \mathrm{pH}$}

According to Table 1 , type and concentration of the components had a significant effect on the $\mathrm{pH}$ of the nanoemulsion $(\mathrm{p}<0.05)$. The $\mathrm{pH}$ decreased as the gum arabic content increased due to the chemical structure of this gum (D-glucoronic acid, L-ramnoz, D-galactoz, L-arabinoz and 2\% protein) (Dickinson, 2003).

\subsection{Particle size of emulsions}

Table 2 shows that the average particle size varied as the composition varied (gum, protein or their combination). The composition of the wall had significant effect on the average diameter of the droplets $(\mathrm{p}<0.05)$. Overall, the particle size decreased significantly with an increase in the ratio of gum arabic as a substitute for WPC.

Gum arabic and WPC were used in the wall composition for encapsulation of the fish oil droplets. The size of the fish oil droplets is a major factor in determination of emulsion properties such as stability. The droplet size depends on factors such as the amount and type of emulsifier, phase type, $\mathrm{pH}$ and preparation method of emulsion (Izquierdo et al., 2002) and also on the ratio of components, speed of stirrer, sequence and rate of adding ingredients (Klinkesorn et al., 2005). The nanoparticle size in emulsions containing gum arabic depends on the wall composition, concentration of the gum, mixing conditions and emulsifier used (Ghayempour \& Mortazavi, 2015). The results showed that the particle size decreased as the gum arabic ratio increased. The highly branched structure of gum arabic works as an emulsifier and reduces the particle size through covalent bonding of the oil droplets and the branches. As the emulsification capacity of the wall increased, the migration of ingredients to the capsule surface decreased.

The results also showed that increasing the WPC ration increased the size of the emulsion droplets. This could be because of the association or blending of droplets due to repulsion of WPC by Tween 80 from the interface of the oil-water droplets in the aqueous phase, alteration of WPC conformation through a van der Waals interaction with the Tween 80 and the consequent decrease in emulsifier capacity or cross-binding between droplets (Jafari et al., 2008). Najaf-Najafi et al. (2010) investigated the encapsulation of castor oil with walls composed of whey protein and pectin. They showed that the type and concentration of the wall affected the particle size and that the modified starch produced bigger particles than the defatted skim milk, which is in agreement with the results of the current research. Our results are similar with findings of Wang et al. (2006), which showed that increasing the protein concentration from $0.5 \%$ to $1.25 \%$ significantly increased the particle size of the emulsion.

\subsection{Zeta potential}

Table 3 shows that the type and concentration of the wall had a significant effect on zeta potential $(\mathrm{p}<0.05)$. Different parameters affect the surface charge, electrophoretic mobility and zeta potential of complexes. These include the $\mathrm{pH}$, ionic strength, type, concentration and ratio of wall biopolymer and type of core. A common method for determination of electrostatic characteristics of ionized samples such as hydrocolloids is zeta potential determination, which represents the overall charge of the particles in an aqueous medium. This parameter is a good marker for the surface charge of particles, the repulsion forces between them and the stability of the system. Determination of

Table 1. $\mathrm{pH}$ of samples (mean $\pm \mathrm{SD})$.

\begin{tabular}{ccc}
\hline Sample & Wall material (gum arabic + WPC) & $\mathrm{pH}$ \\
\hline 1 & $0+20$ & $0.02^{\mathrm{C}} \pm 6.17$ \\
2 & $10+10$ & $0.04^{\mathrm{C}} \pm 6.00$ \\
3 & $12+8$ & $0.04^{\mathrm{B}} \pm 5.74$ \\
4 & $16+4$ & $0.12^{\mathrm{A}} \pm 5.50$ \\
5 & $20+0$ & $0.02^{\mathrm{A}} \pm 5.33$ \\
\hline
\end{tabular}

Values in the same column with same latter have no significant difference $(\mathrm{p}>0.05)$. WPC: Whey Protein Concentrate.

Table 2. Diameter of emulsion droplet $(\mathrm{nm})$ of samples (mean $\pm \mathrm{SD})$.

\begin{tabular}{ccc}
\hline Sample & $\begin{array}{c}\text { Wall material } \\
\text { (gum arabicand WPC) }\end{array}$ & $\begin{array}{c}\text { Diameter of emulsion } \\
\text { droplet }\end{array}$ \\
\hline 1 & $0+20$ & $1.20^{\mathrm{E}} \pm 114.67$ \\
2 & $10+10$ & $1.53^{\mathrm{D}} \pm 103$ \\
3 & $12+8$ & $1.73^{\mathrm{C}} \pm 84$ \\
4 & $16+4$ & $2.08^{\mathrm{B}} \pm 65$ \\
5 & $20+0$ & $1.53^{\mathrm{A}} \pm 50$ \\
\hline
\end{tabular}

Values in the same column with same latter have no significant difference $(\mathrm{p}>0.05)$. WPC: Whey Protein Concentrate.

Table 3. Zeta potential value $(\mathrm{mV})$ of samples (mean $\pm \mathrm{SD})$.

\begin{tabular}{ccc}
\hline Sample & Wall material (gum arabicand WPC) & Zeta potential \\
\hline 1 & $0+20$ & $0.02^{\mathrm{E}} \pm-2.52$ \\
2 & $10+10$ & $0.07^{\mathrm{D}} \pm-3.20$ \\
3 & $12+8$ & $0.12^{\mathrm{C}} \pm-3.80$ \\
4 & $16+4$ & $0.08^{\mathrm{B}} \pm-5.00$ \\
5 & $20+0$ & $0.12^{\mathrm{A}} \pm-7.00$ \\
\hline
\end{tabular}

Values in the same column with same latter have no significant difference $(p>0.05)$. WPC: Whey Protein Concentrate. 
the zeta potential is a good indicator for controlling aggregation and sedimentation, which are important factors affecting the stability of colloidal systems (Wu et al., 2011).

The results indicate that increasing the gum arabic/WPC ratio induced changes in the surface charge and zeta potential, making it more negative. The presence of electrostatic repulsion forces is crucial for prevention of aggregation and improving stability. A decrease in the gum arabic content caused particles to rapidly aggregate and precipitate because, in this situation, the negative charge largely decreased and the zeta potential diminished, preventing a sufficiently strong repulsion force in the complex. Consequently, the particles aggregated and precipitated. Tween 80 has no charged group in its structure and, thus, has no effect on zeta potential.

Campo et al. (2017) encapsulated chia seed oil with chia mucilage as wall material and reported a zeta potential of $-11.58 \pm 1.8 \mathrm{mV}$. Herculano et al. (2015) nanoencapsulated Eucalyptus staigeriana essential oil with cashew gum and observed a zeta potential of -10.58 to $24.5 \mathrm{mV}$. The negative zeta potential of nanoparticles in ionic gum like chia seeds and cashews may be due to the presence of carboxyl groups (carboxylated form; $\mathrm{Coo}^{-}$) which induce a negative charge. Lutz et al. (2009) produced an emulsion with whey protein and pectin. They found that the highest zeta potential was at a $\mathrm{pH}$ approaching 6 . They also showed that the zeta potential of the complex was positive at $\mathrm{pH}=2(+18 \mathrm{mV})$ because the protein was under the isoelectric point. As it approached the isoelectric point $(\mathrm{pH}=4)$, the zeta potential of the complex was near zero $(-7 \mathrm{mV})$, but was negative above this $\mathrm{pH}(-28 \mathrm{mV})$.

Mozafari et al. (2006) found that all vitamins containing liposomes have a zeta potential above $-40 \mathrm{mV}$, which demonstrates the role of electrostatic repulsion forces in prevention of aggregation over time. When the total charge of the particles increases, the particles repulse each other and prevent aggregation. Determination of the zeta potential is important for controlling aggregation and precipitationof nano-liposomes and stabilizing them.

\subsection{Moisture content}

Table 4 shows the moisture content versus the composition. The wall composition significantly influenced the moisture content $(\mathrm{p}<0.05)$. Overall, the particle size decreased significantly as the percentage of gum arabic increased. Because hydrocolloids can increase water absorption and retain moisture in products (Kohajdova \& Karovicova, 2009), samples with higher gum arabic contents had higher moisture contents than those with a higher WPC content. This variation in moisture content could be explained by the difference in the number of water-bonding groups in the gum arabic and WPC.

When gum arabic alone was used as the wall material, the moisture content increased as the wall concentration decreased, probably because the hydrocolloids increased the water-bonding capacity and maintained the moisture content (Kohajdova \& Karovicova, 2009). This can explain the higher moisture content in the samples with gum arabic in comparison to those with WPC. As expected, water absorption increased due to the hydrophilic nature of the hydrocolloid biopolymer, which is likely the reason why the samples with $20 \%$ gum arabic had a higher moisture content (Saberi et al., 2014).

Najaf-Najafi et al. (2010) showed that the moisture content of encapsulated castor oil dried in a spray-drier was higher than that dried in a freeze-drier. They also showed that the type and percentage of crust material strongly affected the moisture content of the dried powder. They concluded that emulsions prepared with Hi-cap 100 lost more water during drying, which decreased the moisture content of the final product because of difference in the number of water-bonding groups in Hi-cap 100 and milk protein.

\subsection{Surface oil}

Determination of the surface oil in samples revealed that changes in the wall composition and ratio significantly influenced the surface oil $(\mathrm{p}<0.05)$ such that the highest surface oil content was for samples with a higher WPC content. The lowest surface oil content was recorded for samples with a higher gum arabic content (Table 5).

The diffusion of oil to the surface of the capsules is not suitable because it causes oil oxidation. This is a concern for nanocapsules and oil content in capsules. In this research, the surface oil decreased as the wall concentration increased. Assessment of the wall components indicated that WPC increased surface oil in comparison with gum arabic. This could be due to the denaturation of the protein structure during emulsification and drying, which decreased the oil-holding capacity. The results showed that gum arabic was more resistant to this situation.

The size of the emulsion can also affect the surface oil. It appears that the molecular size has an influence on the aromatics lost during encapsulation. Larger droplets have lower surface/volume ratios, which will retain the aromatic component better but needs a longer drying time to form a crust. This lag time increases the loss of the aromatics. Generally, aromatic components are better retained in small droplets of emulsion

Table 4. Moisture content (\%) of samples (mean \pm SD).

\begin{tabular}{ccc}
\hline Sample & Wall material (gum arabicand WPC) & Moisture \\
\hline 1 & $0+20$ & $0.04^{\mathrm{A}} \pm 2.20$ \\
2 & $10+10$ & $0.03^{\mathrm{B}} \pm 2.42$ \\
3 & $12+8$ & $0.03^{\mathrm{C}} \pm 2.86$ \\
4 & $16+4$ & $0.04^{\mathrm{D}} \pm 2.97$ \\
5 & $20-0$ & $0.02^{\mathrm{E}} \pm 3.16$ \\
\hline
\end{tabular}

Values in the same column with same latter have no significant difference $(\mathrm{p}>0.05)$. WPC: Whey Protein Concentrate.

Table 5. Surface oil (mg/100 g) of samples (mean \pm SD).

\begin{tabular}{ccc}
\hline Sample & Wall material (gum arabicand WPC) & Surface oil \\
\hline 1 & $0+20$ & $0.99^{\mathrm{D}} \pm 73.33$ \\
2 & $10+10$ & $1.74^{\mathrm{D}} \pm 70.00$ \\
3 & $12+8$ & $0.78^{\mathrm{C}} \pm 63.00$ \\
4 & $16+4$ & $2.57^{\mathrm{B}} \pm 46.67$ \\
5 & $20+0$ & $1.95^{\mathrm{A}} \pm 39.00$ \\
\hline
\end{tabular}

Values in the same column with same latter have no significant difference $(p>0.05)$. WPC: Whey Protein Concentrate. 
when the surface oil in the nanocapsule decreases. Research has shown similar results for the particle size of the powder having no significant influence on the surface oil content. Other factors, including as the size of the emulsion droplets and the amount of volatile ingredients such as aromatic components, can influence the capsulated and unencapsulated oil (Soottitantawata et al., 2005). Jafari et al. (2008) and other studies have proven that the surface oil increases significantly with an increase in the size of the emulsion droplets due to destabilization (or creaming) of the emulsion by larger droplets, which is in agreement with the results of this study.

Davidov-Pardo et al. (2008) found that the particle size of emulsions directly affected the surface oil content. They showed that smaller oil droplets were effectively encapsulated in the matrix of the wall component. The presence of oil at the surface of the powder has been found to be undesirable and leads to wettability and dispersability of the powder, which causes oxidation and develops rancidity (Jafari et al., 2008). Najaf-Najafi et al. (2010) investigated castor oil encapsulation with defatted milk powder and Hi-cap 100 and showed that, in comparison to Hi-cap 100, defatted dried milk powder had a higher percentage of surface oil and lower percentage of encapsulated components because of the denaturation of protein during emulsification and drying, which reduced the ability of the core to retain encapsulated components. It appears that Hi-cap 100 improved resistance to environmental conditions. In fact, damage to the integrity of the surface (cracks or shrinkage) and defects in the surface were observed in particles of defatted milk powder that increased the surface of the capsules and surface oil. They observed a higher surface oil content in the capsule encapsulated in defatted milk powder.

\subsection{Encapsulation efficiency}

The determination of the EE in samples showed that changes in the wall components and their ratios significantly affected encapsulation efficiency $(\mathrm{p}<0.05)$. Table 6 shows that capsules with $20 \%$ gum arabic and $2 \%$ emulsifier had the highest EE. The positive effect of wall concentration on retention of encapsulated components showed that an increase in the ratio of wall materials increased the formation rate and thickness of the semi-permeable layer around the fish oil and the oil expelled decreased according to selective diffusion theory. This theory proposes that a decrease in water at the surface of the droplets decreases the diffusion coefficient of volatile compounds several times more than for that of water. While water continuously migrates through the crust at a specific rate during drying; volatile compounds and other ingredients of the lipid phase diffuse at a negligible rate because they are trapped inside a mass of dried matter (wall). This solid coverage, as a semi-permeable member, allows the water to leak out, but decreases or even prevents the expulsion of volatile compounds. Volatile compounds can leave the particles before the crust forms, possibly in the early stages of drying.

A decrease in encapsulated volatile compounds may occur from the ability of this component to cross through the crust. In this condition, the component can exit through the walls by diffusion or by crossing along pores or canals. The concentration
Table 6. Encapsulation efficiency (\%) of samples (mean \pm SD).

\begin{tabular}{ccc}
\hline Sample & $\begin{array}{c}\text { Wall material } \\
\text { (gum arabicand WPC) }\end{array}$ & $\begin{array}{c}\text { Encapsulation } \\
\text { efficiency }\end{array}$ \\
\hline 1 & $0+20$ & $0.69^{\mathrm{C}} \pm 65.20$ \\
2 & $10+10$ & $1.07^{\mathrm{C}} \pm 67.42$ \\
3 & $12+8$ & $0.73^{\mathrm{B}} \pm 71.34$ \\
4 & $16+4$ & $1.12^{\mathrm{A}} \pm 80.78$ \\
5 & $20+0$ & $0.97^{\mathrm{A}} \pm 81.71$ \\
\hline
\end{tabular}

Values in the same column with same latter have no significant difference $(\mathrm{p}>0.05)$. WPC: Whey Protein Concentrate.

of wall material and the temperature of drying are important because they have a major effect on the formation of the protective layer. Investigation is ongoing about other factors that could affect volatile compound retention in capsules. It has been reported that the type and composition of encapsulated ingredients and wall materials are important. EE represents the degree of surface oil on particles and the degree to which the wall can prevent encapsulated oil extraction. It has been observed that larger emulsion droplets allow increased expulsion of the surface oil content.

Particles encapsulated with gum arabic had better EE values and lower surface oil because of the smaller particles. This difference in oil holding capacity may be due to the difference in the molecular weight of the wall materials. An increase in molecular weight increased the material holding capacity, effective oil droplet distribution in solid materials and the low percentage of surface oil (Klaypradit \& Huang, 2008). An increase in viscosity in the continuous phase decreased the mobility of the droplets and provided enough time for adsorption of the emulsifier onto the surface of the water and oil droplets, which reinforced droplets against sedimentation and stabilized the emulsion, creating capsules with higher EE values after drying (Makri \& Doxastakis, 2006). Ilyasoglu \& Nehir El (2014) encapsulated EPA/DHA with gum arabic and sodium caseinate and recorded an EE for the encapsulated oil of $78.88 \% \pm 2.98 \%$ for the protein-polysaccharose complex.

Zimet \& Livney (2009) achieved $64 \% \pm 10 \%$ EE for nanoencapsulation of DHA with betalactoglobulin-pectin. Peniche et al. (2004) reported an EE of 42\%-92\% for encapsulation with various percentages of alginate, which was in agreement with the results of the present research. Badee et al. (2012) encapsulated peppermint oil with gum arabic, maltodextrin and their combination by spray-drying. Their results showed that the highest oil retention of $81 \%$ and $80 \%$, respectively, was during drying for gum arabic and the gum arabic:maltodextrin 1:1 combination, which was in agreement with the results of other research. Similar results have been reported by Krishnan et al. (2005), who encapsulated cardamom oleoresin in maltodextrin-modified starch-gum arabic. They concluded that an increase in gum arabic increased encapsulation efficiency.

\section{Conclusion}

It was concluded from this study that the type and concentration of biopolymers as wall materials affected the droplet size, zeta potential, $\mathrm{pH}$, moisture, surface oil content and encapsulation 
efficiency for nanoencapsulation. A comparison of WPC and gum arabic as wall materials showed that gum arabic was more suitable for nanoencapsulation and could appropriately maintain volatile compounds within the capsules. The findings also showed that the type and concentration of wall material significantly affected encapsulation efficiency such that emulsions with higher concentrations of wall materials increased encapsulation efficiency.

\section{References}

Association of Official Analytical Chemists - AOAC. (2000). Official methods of analysis (16th ed.). Washington: AOAC.

Badee, A., Amal, E., El- Kader, A., \& Hanan, M. (2012). Microencapsulation of peppermint oil by spray drying. Australian Journal of Basic and Applied Sciences, 6, 499-504.

Campo, C., Santos, P. P., Costa, T. M. H., Paese, K., Guterres, S. S., Rios, A. O., \& Flôres, S. H. (2017). Nanoencapsulation of chia seed oil with chia mucilage (Salvia hispanicaL.) as wall material: characterization and stability evaluation. Food Chemistry, 234, 1-9. http://dx.doi. org/10.1016/j.foodchem.2017.04.153. PMid:28551210.

Considine, T., Patel, H. A., Singh, H., \& Creamer, L. K. (2007). Influence of binding conjugated linoleic acid and myristic acid on the heat- and high-pressureinduced unfolding and aggregation of [beta]- lactoglobulin B. Food Chemistry, 102(4), 1270-1280. http:// dx.doi.org/10.1016/j.foodchem.2006.07.022.

Davidov-Pardo, G., Roccia, P., Roccia, D., Saldgo, A. E., \& Leon, R. (2008). Utilization of different wall materials fish oil evaluation of its behavior in bread products. American Journal of Food Technology, 6, 384-393. http://dx.doi.org/10.3923/ajft.2008.384.393.

Dickinson, E. (2003). Milk protein interfacial layers and the influence on the properties of dispersed systems. Food Hydrocolloids, 17(1), 25-39. http://dx.doi.org/10.1016/S0268-005X(01)00120-5.

Ghayempour, S., \& Mortazavi, S. M. (2015). Preparation and investigation of sodium alginate nanocapsules by different microemulsification devices. Journal of Applied Polymer Science, 132(17), 344-349. http:// dx.doi.org/10.1002/app.41904.

Habib, S. M., Amr, A. S., \& Hamadneh, I. M. (2012). Nanoencapsulation of alpha- linolenic acid with modified emulsion method. Journal of the American Oil Chemists' Society, 89(4), 695-703. http://dx.doi. org/10.1007/s11746-011-1960-3.

Herculano, E. D., Paula, H. C. B., Figueiredo, E. A. T., Dias, F. G. B., \& Pereira, V. D. A. (2015). Physicochemical and antimicrobial properties of nanoencapsulated Eucalyptus staigeriana essential oil. Lebensmittel-Wissenschaft + Technologie, 61(2), 484-491. http:// dx.doi.org/10.1016/j.lwt.2014.12.001.

Ilyasoglu, H., \& Nehir El, S. (2014). Nanoencapsulation of EPA/DHA with sodium caseinate- gum Arabic complex and its usage in the enrichment of fruit juice. Journal of Food Science and Technology, 56, 461-468. http://dx.doi.org/10.1016\%2Fj.lwt.2013.12.002.

Izquierdo, P., Esquena, J., Tadros, T. F., Dederen, C., Garcia, M. J., Azemar, N., \& Solans, C. (2002). Formation and stability of nanoemulsions prepared using the phase inversion tempreture method. Langmuir, 1(1), 26-30. http://dx.doi.org/10.1021/la010808c.

Jafari, S. M., Assadpoor, E., Bhandari, B., \& He, Y. (2008). Nano-particle encapsulation of fish oil by spray drying. Food Research International, 41(2), 172-183. http://dx.doi.org/10.1016/j.foodres.2007.11.002.

Jimenez, M., García, H. S., \& Beristain, C. I. (2004). Spray-drying microencapsulation and oxidative stability of conjugated linoleic acid. European Food Research and Technology, 219, 588-592. http:// dx.doi.org/10.1007/s00217-004-0992-4.
Kaushik, V., \& Roos, Y. H. (2007). Limonene encapsulation in freez-drying of gum arabic-sucrose-gelatin system. Lebensmittel-Wissenschaft + Technologie, 40(8), 1381-1391. http://dx.doi.org/10.1016/j. lwt.2006.10.008.

Klaypradit, W., \& Huang, Y. (2008). Fish oil encapsulation with chitosan using ultrasonic atomizer. Lebensmittel-Wissenschaft + Technologie, 41(6), 1133-1139. http://dx.doi.org/10.1016/j.lwt.2007.06.014.

Klinkesorn, U., Sophanodora, P., Chinachoti, P., Decker, E., \& McClements, D. J. (2005). Encapsulation of emulsified tuna oil in two-layered interfacial membranes prepared using electrostatic layer-by-layer deposition. Food Hydrocolloids, 19(6), 1044-1053. http://dx.doi. org/10.1016/j.foodhyd.2005.01.006.

Klinkesorn, U., Sophanodora, P., Chinachoti, P., Decker, E., \& McClements, D. J. (2006). Characterization of spray- dried tuna oil emulsified in two-layered interfacial membranes prepared using electrostatic layer-by-layer deposition. Food Research International, 39(4), 449457. http://dx.doi.org/10.1016/j.foodres.2005.09.008.

Kohajdova, Z., \& Karovicova, J. (2009). Application of hydrocolloids as baking improvers. Chemistry of Materials, 63, 26-38.

Krishnan, S., Kshirsagar, A., \& Singhal, R. (2005). The use of gum arabicand modified starch in the microencapsulation of a food flavoring agent. Carbohydrate Polymers, 62(4), 309-315. http:// dx.doi.org/doi.org/10.1016/j.carbpol.2005.03.020.

Liu, Z., Jiao, Y., Wang, Y., Zhou, C., \& Zhang, Z. (2008). Polysaccharidesbased nanoparticles as drug delivery systems. Advanced Drug Delivery Reviews, 60(15), 1650-1662. http://dx.doi.org/10.1016/j. addr.2008.09.001. PMid:18848591.

Lopez-Huertas, E. (2010). Health effects of oleic acid and long chain omega-3 fatty acids (EPA and DHA) enriched milks, A review of intervention studies. Pharmacological Research, 61(3), 200-207. http://dx.doi.org/10.1016/j.phrs.2009.10.007. PMid:19897038.

Lutz, R., Aserin, A., Wicker, L., \& Garti, N. (2009). Double emulsions stabilized by a charged complex of modified pectin and whey protein isolate. Colloids and Surfaces. B, Biointerfaces, 72(1), 121-127. http:// dx.doi.org/10.1016/j.colsurfb.2009.03.024. PMid:19403278.

Makri, E. A., \& Doxastakis, G. I. (2006). Study of emulsions and foam stabilized with Phaseolus vulgaris or Phaseolus coccineus with the addition of Xanthan or NaCl. Journal of the Science of Food and Agriculture, 86(12), 1863-1870. http://dx.doi.org/10.1002/jsfa.2534.

Mozafari, M. R., Flanagan, J., Matia-Merino, L., Awati, A., Omri, A., Suntres, Z. E., \& Singh, H. (2006). Recent trends in the lipid-based nanoencapsulation of antioxidants and their role in foods. Journal of the Science of Food and Agriculture, 86(13), 2038-2045. http:// dx.doi.org/10.1002/jsfa.2576.

Mutka, J. R., \& Nelson, D. B. (1988). Preparation of encapsulated flavors with high flavor level. Food Technology, 42, 154-157.

Najaf Najafi, M., Kadkhodaee, R., \& Mortazavi, S. A. (2010). Effect of drying process and wall material on the properties of encapsulated cardamom oil. Food Biophysics, 32, 245-253. http://dx.doi.org/10.1007/ s11483-010-9176-x.

Peniche, C., Howland, I., Carrillo, O., Zaldivar, C., \& Argüelles-Monal, W. (2004). Formation and stability of shark oil liver loaded chitosan/ calcium alginate capsules. Food Hydrocolloids, 18(5), 865-871. http:// dx.doi.org/10.1016/j.foodhyd.2004.02.001.

Philips, G. O., \& Williams, P. A. (2000). Handbook of hydrocolloids. Florida: CRC Press.

Rosenberg, M. (1997). U.S. Patent no. 5, 601,760. Oakland: California Corporation.

Saberi, M., Hashemiravan, M., \& Farhadyar, N. (2014). Influence of casein and inulin on the properties of nano-particle encapsulation 
of fish oil. Journal of Biodiversity and Environmental Sciences, 4(2), 318-326.

Shiga, H., Yoshii, H., Nishiyama, T., Furuta, T., Forssele, P., Poutanen, K., \& Linko, P. (2001). Flavor encapsulation and release characteristics of spray-dried powder by the blended encapsulant of cyclodexterin and Arabic gum. Drying Technology, 19(7), 1385-1395. http://dx.doi. org/10.1081/DRT-100105295.

Soottitantawata, A., Bigeardb, F., Yoshiia, H., Furutaa, T., Ohkawarac, M., \& Linkod, P. (2005). Microencapsulation of 1-menthol by spray drying and its release characteristics. Innovative Food Science \& Emerging Technologies, 6(1), 107-114. http://dx.doi.org/10.1016/j. ifset.2004.11.007.

Wang, T., Deng, Y., Geng, Y., Gao, Z., Zou, J., \& Wang, Z. (2006). Preparation of submicron unilamellar liposomes by freeze-drying double emulsions. Biochimica et Biophysica Acta, 1758(2), 222-231. http://dx.doi.org/10.1016/j.bbamem.2006.01.023. PMid:16563340.

Wu, L., Zhang, J., \& Watanabe, W. (2011). Physical and chemical stability of drug nanoparticles. Advanced Drug Delivery Reviews, 63(6), 456469. http://dx.doi.org/10.1016/j.addr.2011.02.001. PMid:21315781.

Ye, A., Flanagan, J., \& Singh, H. (2006). Formation of stable nanoparticles via electrostatic complex between sodium caseinate and Arabic gum. Biopolymers, 82(2), 121-133. http://dx.doi.org/10.1002/bip.20465. PMid:16453308.

Zimet, P., \& Livney, Y. D. (2009). Beta-lactoglobulin and nanocomplexes with pectin as vehicles for -3 poly unsaturated fatty acids. Food Hydrocolloids, 23(4), 1120-1126. http://dx.doi.org/10.1016/j. foodhyd.2008.10.008. 